\title{
A EDUCAÇÃO PARA O DESENVOLVIMENTO LOCAL: UMA ANÁLISE DA EDUCAÇÃO BRASILEIRA FRENTE AO ENSINO FINLANDÊS
}

\author{
CRISTINA NUNES ROCHA ${ }^{1}$, KÁTIA ELIANE SANTOS AVELAR ${ }^{2}$
}

\footnotetext{
1 Mestranda do Programa de Pós-Graduação em Desenvolvimento Local, do Centro Universitário Augusto Motta, UNISUAM, Rio de Janeiro, RJ.

2 Doutora em Ciências pela UFRJ. Docente e Pesquisadora do Programa de Pós-Graduação em Desenvolvimento Local do Centro Universitário Augusto Motta, UNISUAM, Rio de Janeiro, RJ.
}

\section{RESUMO}

O presente artigo teve por objetivo desenvolver um estudo sobre os indicadores da educação brasileira e suas políticas. $O$ foco principal da pesquisa é a educação brasileira, sendo o modelo de ensino da Finlândia, uma proposta a ser seguida e adaptada à educação aplicada no Brasil. O ensino da Finlândia tem a educação como um dos principais agentes para o desenvolvimento local. O método de ensino finlandês é destaque em todo o mundo, por conta dos seus resultados acadêmicos excelentes no exame do Programa Internacional de Avaliação de Alunos (PISA), sendo considerado um país inovador em metodologias ativas de ensino. $\mathrm{O}$ estudo aborda também, as exigências da Organização para a Cooperação e Desenvolvimento Econômico (OCDE) no âmbito educacional frente à realidade da Educação brasileira, cujo desempenho tem sido medido pelo Índice de Desenvolvimento da Educação Básica (IDEB). Para atingir tal propósito, será utilizada uma metodologia descritiva, de caráter exploratório. Partiuse de uma revisão literária embasada em pesquisas e indicadores publicados, além de publicações de autores do âmbito da educação. Observou-se, na revisão literária, que o Brasil realizou inúmeras reformas educacionais ao longo do tempo, propondo melhorias, todavia sem muito sucesso na prática. As consequências vêm sendo refletidas nos exames que visam medir a qualidade da educação de modo interno e externo. O Brasil possui muitas escolas, porém, algumas delas estão em situação precária. Para alcançar o êxito no âmbito educacional, é preciso repensar as políticas para a educação que vem sendo adotadas pelo país.

Palavras-chave: Finlândia; Educação Básica; Decreto n.13.005/2014; Educação no Brasil.

\section{EDUCATION FOR LOCAL DEVELOPMENT: AN ANALYSIS OF BRAZILIAN EDUCATION IN FRONT OF FINNISH EDUCATION}

\begin{abstract}
This article aimed to develop a study on the indicators of Brazilian education and its policies. The main focus of the research is Brazilian education, being Finland's teaching model, a proposal to be followed and adapted to applied education in Brazil. Finnish
\end{abstract}


teaching has education as one of the main agents for local development. The Finnish teaching method is highlighted throughout the world, due to its excellent academic results in the PISA (Programme for International Student Assessment) exam, being considered an innovative country in active teaching methodologies. The study also addresses the requirements of the OECD (Organization for Economic Cooperation and Development) in the educational field in the face of the reality of Brazilian education, whose performance has been measured by IDEB (Basic Education Development Index). To achieve this purpose, an exploratory descriptive methodology will be used. It started with a literary review based on published research and indicators, in addition to publications by authors in the field of education. It was observed in the literary review that Brazil carried out numerous educational reforms over time, proposing improvements, however without much success in practice. The consequences have been reflected in exams that aim to measure the quality of education internally and externally. Brazil has many schools, but some of them are in a precarious situation. To achieve success in the educational field, it is necessary to rethink the policies for education that have been adopted by the country.

Keywords: Finland; Basic Education; Decree n. 13.005/2014; Education in Brazil.

\section{INTRODUÇÃO}

Desde a fase inicial da educação no Brasil, os padres jesuítas, que eram parte dos colonizadores portugueses, tinham o objetivo de catequizar e educar o povo nativo. No contexto da educação, essa foi a primeira iniciativa de implantar na cultura brasileira os métodos de ensino humanistas. Porém, fundamentadas na ordem e disciplina dentro das salas de aulas, essa prática pedagógica ainda existe na atualidade, fruto da bagagem cultural e histórica da colonização Portuguesa. No final do século XIX, consagrada a Proclamação da República no Brasil, a alfabetização era privilégio somente das elites. O poder latifundiário dominava a república e o ensino era exclusividade da igreja católica (MESQUIDA, 2013).

Com o passar do tempo, o crescimento e o desmembramento do ensino básico no Brasil chama a atenção com os números crescentes. Na década de 1990, mais de 40\% dos alunos terminavam o ensino básico com atraso de dois anos; em 2014, essa mesma análise mostra que essa porcentagem diminuiu para 19,1\%. A taxa de jovens entre $15 \mathrm{e}$ 17 anos matriculados em 1992 era de 41,9\%. Já em 2014, passou para 88,7\%. Os números são referentes à taxa bruta de matriculados, mas nem todos chegam à conclusão do ensino Médio. Devido a evolução das políticas públicas depois de 20 anos 
passados, os alunos têm mais chances de ingressar em cursos universitários (SCHWARTZMAN, 2016).

Segundo Moraes (2017), a educação básica teve um avanço considerável desde a década de 1990, todavia, ainda está abaixo da média do esperado pelo Ministério da Educação. Essa disparidade se torna evidente quando comparada com países como a Finlândia, notada pelo desempenho alto na educação básica. O estudo torna-se formativo e reflexivo, sendo assim relevante para entendimento das políticas de ensino da educação básica. Na busca de entender o "que está por trás de exemplos bemsucedidos, pode-se refletir sobre a própria trajetória das políticas educacionais e sobre os caminhos de reforma que se vislumbram no horizonte" (BRITTO, 2013, p. 18).

O problema abordado nesta pesquisa relaciona-se com o baixo rendimento do Brasil nos exames Programa Internacional de Avaliação de Alunos (PISA) e no Índice de Desenvolvimento da Educação Básica (IDEB), trazendo à tona a baixa qualidade da educação básica. Com o intuito de entender o que está acontecendo na educação brasileira, descreve-se uma evolução das principais reformas educacionais que deram origem à educação praticada atualmente.

Nesse contexto, fez-se necessária a análise da legislação vigente, em destaque o decreto n. 13.005/2014 criado pelo Plano Nacional de Educação (PNE), para uma melhor compreensão das políticas da educação. A metodologia de ensino finlandês não é o foco principal deste estudo, mas foi utilizada como subsídio para a pesquisa, com o intuito de apresentar um modelo educacional que se mostra funcional na prática. Esse estudo buscou dados pertinentes na literatura científica sobre o ensino na Finlândia, para contribuir com a compreensão das diferenças entre esses dois países na forma de ensinar.

O objetivo da pesquisa é analisar os indicadores da educação brasileira e suas políticas, apresentando também o ensino da Finlândia como um método de ensino eficaz, no qual a educação começa individualmente, refletida no convívio em sociedade, e tem como função social, o bem comum a todos, promovendo desenvolvimento e melhorias para toda a nação finlandesa (BITTAR; BITTAR, 2012).

A pesquisa utiliza o método descritivo, exploratório, e é embasada em fontes bibliográficas produzidas por autores do âmbito da pesquisa, dados governamentais, modelo de ensino da Finlândia e indicadores de qualidade da educação básica. 


\section{METODOLOGIA DA PESQUISA}

Foi realizada uma seleção de artigos publicados em sites voltados para a pesquisa científica, com informações relevantes para a educação, como por exemplo, o rendimento escolar do Brasil em comparação aos países membros da OCDE. Para a redação do artigo, houve acesso on-line às leis que regem a educação básica por meio do Diário Oficial da União, que contém informações relevantes para a compreensão da evolução das políticas educacionais brasileiras, assim como a legislação vigente, como o decreto n.13.005/2014, no qual Plano Nacional de Educação (PNE) lista as metas a serem alcançadas pela educação básica até 2024.

O presente estudo baseia-se em metodologia descritiva, de caráter exploratório, fundamentada em pesquisas bibliográficas. A revisão literária utiliza pesquisas em endereços eletrônicos governamentais, como Ministério da Educação (MEC), Instituto Nacional de Estudos e Pesquisas Educacionais Anísio Teixeira (INEP) e Organização para a Cooperação e Desenvolvimento Econômico (OCDE). A pesquisa bibliográfica implica em um conjunto ordenado de procedimentos de busca por soluções, atento ao objeto de estudo, e que, por isso, não pode ser aleatório (LIMA; MIOTO, 2007, p. 38).

Para melhor entendimento dos indicadores da qualidade da educação brasileira, foram utilizados como subsídio da pesquisa os sites do MEC e INEP, que apresentam informações relevantes sobre o IDEB e PISA. Foram utilizados também, os dados exibidos on-line pela OCDE sobre as médias da Finlândia nos exames educacionais comparadas às exigências do PISA e as médias do Brasil.

\section{CONTEXTUALIZAÇÃO DA EDUCAÇÃO BRASILEIRA}

A primeira iniciativa educacional no Brasil aconteceu em 1549, materializandose através da vinda dos jesuítas junto com os colonizadores portugueses, com objetivo principal de catequizar e educar os nativos e, assim, formaram a chamada Companhia de Jesus. Estes foram responsáveis por formar os primeiros professores do Brasil colônia. Os jesuítas deixaram sua marca na história, notada até mesmo na educação 
contemporânea praticada no Brasil, através dos métodos e técnicas pedagógicas pautadas na ordem, disciplina e respeito às regras (MESQUIDA, 2013).

Vieira (2001) explica que, em 1932, houve o movimento pela Escola Nova no Brasil, que contou com a participação de alguns intelectuais como Cecília Meireles, Erasmo Pilotto, Fernando de Azevedo, Lourenço Filho e Anísio Teixeira. O conceito inovador de educação motivou reformas políticas na área educacional, como as novas metodologias de ensino pautadas na concepção da formação humana, organização do sistema nacional de ensino e novos métodos para a formação de professores.

O autor citado acima se refere à Escola Nova como um movimento renovador da educação. A pluralidade de ideias geradas nessa época valorizou a atmosfera científica, servindo de referência teórica para a educação e contribuindo significativamente para a implantação de novas metodologias de ensino no Brasil (VIEIRA, 2001).

Ainda na década de 1930, regido pelo Governo Vargas, a revolução industrial motiva o investimento nas funções intelectuais da comunidade; para suprir e alavancar o processo produtivo em meio aos avanços tecnológicos, era necessário contratar mão de obra qualificada e pessoas letradas para operar os maquinários. Vendo a necessidade de investimento na indústria, o governo começou a investir na escola, ou seja, no ensino básico, com o objetivo de qualificar os trabalhadores. Nessa época, nasceram os cursos profissionalizantes, para suprir uma demanda de tarefas específicas das indústrias, como manutenção e reparos especializados (SAVIANI, 2018).

Esse período de estímulo à alfabetização pode ser descrito como o início do processo de transição da massa popular, da ignorância para uma conduta mais crítica e racional do indivíduo. A essência do processo democrático do saber tem a mudança como um dos seus preceitos fundamentais. Porém, a simples superação do analfabetismo não transformaria a rebelião popular em inserção (FREIRE, 2014).

A Escola Nova tornou-se popular no Brasil, com métodos modernos de ensino oriundos de países desenvolvidos, com o propósito de substituir a referência pedagógica tradicional e rígida para um ambiente descontraído e espontâneo, a fim de incentivar a aprendizagem. O professor seria um orientador e estimulador do saber, cercado por materiais didáticos e bibliotecas disponíveis. Esse conceito de educação recebeu algumas críticas dos tradicionalistas da época. Todavia, cabe ressaltar que a Escola Nova contribuiu significativamente para melhoria da qualidade do ensino brasileiro. 
Contudo, a escola pública não tinha condição de aderir a esse método, devido à falta de orçamentos governamentais da época (SAVIANI, 2018).

Os métodos da Escola Nova eram aplicados, em grande parte, no ensino das elites e colégios militares. Este conceito inovador de educação demorou a chegar à rede pública. Portanto, a realidade da alfabetização para a grande massa popular era um processo mecânico: as escolas ensinavam apenas a ler e escrever, e não havia um estímulo ao pensamento crítico e individual. A única preocupação governamental era diminuir os altos índices do analfabetismo. A pedagogia de ensino tradicional tornava cada vez mais distante a participação ativa da população na sociedade (FREIRE, 2014).

Brandão (2007) ressalta que esse poder das elites perpetuou-se por um tempo longo: a partir da década de 1960, a educação no Brasil era controlada pelo governo e as elites. Para manter seus interesses e domínio sobre o povo, ensinava-se o que era conveniente, a fim de manter a população na ignorância de seus direitos. A educação, que deveria ser um bem comum a todos, estava inserida em uma sociedade desigual (BRANDÃO, 2007).

Segundo os relatos de Paulo Freire, em seu livro Educação como Prática da Liberdade, publicado em 1967, não havia estímulo à área científica por parte do governo, desmotivando os intelectuais da época ao desenvolvimento de pesquisas. A saída era buscar refúgio em ideais europeias e norte-americanas, que não representavam o Brasil como ele realmente era. Dessa forma, o país era considerado atrasado cientificamente. A partir do Instituto Superior de Estudos Brasileiro (ISEB), criado em 1955 e extinto pelos militares em 1964, a força do pensamento intelectual brasileiro passou a considerar as perspectivas do país em sua realidade, priorizando a cultura nacional e as descobertas dos intelectuais nacionais (FREIRE, 2014).

No que se referente às políticas educacionais, vale lembrar que, apesar do autoritarismo e ausência da livre democracia na década de 70 , a educação deu um salto em sua política pública durante o regime militar no Brasil. Um marco importante para a nossa história foi a reforma da lei n. 5.692, de 11 de Agosto de 1971, que alterou a oferta do ensino básico à população, que antes compreendia um período de quatro anos, passou então para oito anos de ensino obrigatório, continuando gratuito (BRANDÃO, 2007). Ainda nessa reforma, o Art. $1^{\circ}$ da referida lei incluiu a educação artística como atividade educativa para os estudantes de primeiro e segundo grau (GONÇALVES, 
2011).

Dentre os desafios encontrados pela educação no Brasil, em meados do século XX, permanecia a luta pelas classes vulneráveis da população contra a seletividade por acesso ao ensino de qualidade. Ficou evidente que somente as elites tinham acesso aos melhores colégios e esse foi um estímulo à desigualdade social e de oportunidades do país. Para tentar solucionar o fracasso escolar, criou-se o projeto chamado de educação compensatória, como uma forma de nivelar o ensino e diminuir a marginalidade. Essa proposta trouxe consigo um conjunto de programas destinados a corrigir as deficiências do ensino-pedagógico tradicional (SAVIANI, 2018).

$\mathrm{Na}$ década de 1990, os países desenvolvidos se destacaram na corrida educacional: sua meta era proporcionar ensino de qualidade para a população. Porém, a crise econômica e política enfrentada pelo Brasil nesse período atrasou o desenvolvimento das políticas educacionais. Surgiu então a Lei n. 9.424, com a criação do Fundo de Manutenção e Desenvolvimento do ensino Fundamental e Valorização do Magistério (FUNDEF), voltado ao financiamento das políticas de educação, elaborado pela Emenda Constitucional n. 14, de 12 de setembro de 1996 (GIOLO, 2010).

O FUNDEF, criado pelo governo Fernando Henrique Cardoso (1995-2002), foi ampliado e valorizado pelo governo Luiz Inácio Lula da Silva (2003-2011) e teve um impacto sócio-educacional. Esse recurso compreende desde a Educação Infantil ao ensino de nível Fundamental e Médio. Além disso, o governo Lula também investiu no ensino Superior com a criação de programas para facilitar o acesso das camadas inferiores a este nível de estudo. Os programas e as políticas públicas para o ensino superior não são o foco da pesquisa; porém, vale explanar que, com o investimento no ensino superior, houve uma melhoria significativa no índice de pessoas portadoras de diploma no país (BITTAR; BITTAR, 2012).

Em se tratando do sistema educacional brasileiro, seguramente, as parcerias com os institutos federais também contribuíram para a fiscalização e regulação das políticas e programas educacionais, em prol do desenvolvimento econômico e social. O maior exemplo dessa parceria chama-se Instituto Nacional de Estudos e Pesquisas Educacionais Anísio Teixeira (INEP). Criado em 1937, o INEP se tornou uma autarquia federal e sua função é subsidiar as políticas educacionais, que estão vinculadas ao Ministério da Educação (INEP, 2019). 
O INEP também é responsável por monitorar o PNE, criado pelo congresso federal em 2014. Neste plano, são estabelecidas metas e estratégias para as escolas. O INEP divulga os resultados a cada dois anos, a fim de verificar se os objetivos previstos pelo MEC estão sendo alcançados. Sendo assim, cada município tem o dever de elaborar seu delineamento escolar, levando em consideração os obstáculos e situações específicas de cada localidade (BRASIL, 2019).

O Ministério da Educação, conforme o decreto n. 13.005, de 25 de junho de 2014, divulgou o Plano Nacional de Educação - PNE, Art. $2^{\circ}$ São diretrizes do PNE:

\begin{abstract}
I - erradicação do analfabetismo; II - universalização do atendimento escolar; III - superação das desigualdades educacionais, com ênfase na promoção da cidadania e na erradicação de todas as formas de discriminação; IV melhoria da qualidade da educação; V - formação para o trabalho e para a cidadania, com ênfase nos valores morais e éticos em que se fundamenta a sociedade; VI - promoção do princípio da gestão democrática da educação pública; VII - promoção humanística, científica, cultural e tecnológica do País; VIII - estabelecimento de meta de aplicação de recursos públicos em educação como proporção do Produto Interno Bruto - PIB, que assegure atendimento às necessidades de expansão, com padrão de qualidade e equidade; IX - valorização dos (as) profissionais da educação; X - promoção dos princípios do respeito aos direitos humanos, à diversidade e à sustentabilidade socioambiental (BRASIL, 2014, on-line).
\end{abstract}

O PNE tem vigência de 10 anos, abrangendo o período de 2014 a 2024. Conforme Amaral (2016), o Regime Fiscal, criador da EC (Emenda à Constituição) n. 95/2016, ameaça as diretrizes do PNE citadas acima, pois essa emenda visa congelar as despesas primárias dos poderes executivo, legislativo, judiciário, ministério público e até mesmo defensoria pública da União até 2036. Segundo a autora, o senado justificou a emenda como sendo uma estratégia para redução de gastos. Segundo Ogiba (2018, p. 203), “é essencial que se revogue da EC n 95/2016 que limita a ampliação dos investimentos públicos nas áreas sociais por 20 anos, o que compromete definitivamente todas as metas do PNE".

Ogiba (2018) ainda ressalta que a implantação do PNE é uma missão para todos os níveis das esferas públicas, governo, instituições e toda a sociedade. $\mathrm{O}$ autor comenta, em específico, a diretriz n. VI (promoção do princípio da gestão democrática da educação pública). A autora se preocupa com a mercantilização da educação e com o estímulo da democracia através de políticas públicas nas escolas. O ambiente escolar pode ser considerado o local mais adequado para formação de indivíduos conscientes de seu papel em sociedade. 
O PNE traçou metas arrojadas para o sistema educacional, como, por exemplo, a meta n. I: erradicação do analfabetismo. Conforme pesquisa do Instituto Brasileiro de Geografia e Estatística (IBGE) no último censo realizado em 2017, o Brasil não alcançou a meta do PNE para 2015, projetada em 6,5\%. A taxa de analfabetismo da população maior de 15 anos em 2017 estava em 7\% totalizando 11,5 milhões de pessoas que ainda não sabem ler e nem escrever.

O IBGE ainda ressalta que a meta do PNE era garantir que $85 \%$ dos alunos do ensino médio, ao se formarem, deveriam estar na idade adequada de até 19 anos. Porém, em 2017, a taxa foi de 68\%, bem abaixo do esperado. Para o ensino fundamental, esperava-se que os alunos terminassem aos 16 anos. A projeção do plano de educação era 95\%; porém, em 2017, o índice atingiu $85,6 \%$ até o $9^{\circ}$ ano.

Analisando também a meta n. IX, que trata da valorização dos profissionais da educação, nota-se que já passaram cinco anos e não se observaram melhorias consideráveis para o cumprimento da proposta. Pontes (2019) defende mais investimento na formação continuada dos professores da rede básica de ensino para o desenvolvimento de habilidades específicas, como, por exemplo, a inovação ao apresentar o conteúdo em sala de aula. É necessário dar autonomia aos professores e gestores educacionais, levando em consideração a cultura e o contexto social por região.

Pontes (2019) ainda argumenta sobre a importância da Base Nacional Comum Curricular (BNCC) para o PNE (2014). Segundo o autor, um dos objetivos propostos pelo MEC consiste em sistematizar o currículo da rede pública e privada. O BNCC existe desde a Constituição de 1988 e sua criação reconhece o direito da sociedade no acesso à educação básica, regulamentando e definindo as competências que devem compor o currículo nacional.

Marta (2018) elucida que a Base Nacional Comum Curricular (BNCC) é um documento que estabelece as competências fundamentais que são essenciais no aprendizado durante a Educação Básica. Tais competências são apresentadas de modo linear e são elas: Conhecimento; Pensamento Científico, Crítico e Criativo; Repertório cultural; Comunicação; Cultura digital; Trabalho e projeto de vida; Argumentação; Autoconhecimento e autocuidado; Empatia e Cooperação; Responsabilidade e Cidadania. O processo de estruturação da BNCC sucedeu democraticamente, 
começando em 2015 e sendo concluído no final de 2017, com o reconhecimento pelo MEC.

A reforma educacional, realizada no Governo Temer em 2016, oficializou, através da MP 746/2016, a implantação da reforma na BNCC, para o ensino médio. Ficou definido, a partir dessa medida, que o sistema de ensino deverá dar ênfase nas disciplinas de matemática, ciências da natureza, linguagens, ciências humanas e formação técnica e profissional. Em referência à língua estrangeira, o inglês é a prioridade de ensino (BRASIL, 2019).

Segundo Young (2016, p. 14), o currículo escolar bem elaborado torna o aluno mais poderoso em seu conhecimento, facilitando a superação dos desafios que a vida vai lhe proporcionar. "Entretanto, diferentes disciplinas oferecem aos alunos diferentes tipos de poder", e contribuem para a compreensão de como as instituições e pessoas se comportam na sociedade. A criança que tem um ensino de baixa qualidade não estará pronta para acompanhar e nem competir no mercado de trabalho.

Visando acompanhar as diretrizes do artigo $2^{\circ}$ do PNE citadas neste estudo, foi criado o Sistema Nacional de Avaliação da Educação Básica (SINAEB). Sua finalidade é dar suporte ao INEP, mensurando de forma mais precisa os resultados do desenvolvimento dos alunos da educação básica. Segundo o Ministério da Educação (2020), o SINAEB é uma avaliação feita nas escolas a cada dois anos, substituindo o antigo sistema Sistema de Avaliação da Educação Básica (SAEB). Este modelo de avaliação permite mensurar a qualidade da educação ofertada em cada escola, tendo como principal intuito "produzir informações a partir de indicadores de rendimento escolar - referente ao desempenho dos estudantes, apurado em exames nacionais - e de avaliação institucional, que levanta dados relativos a características como perfil do aluno e dos profissionais da educação" (MEC, 2020, s.p.).

Neto (2016) considera importante acompanhar o desenvolvimento educacional do país. Porém, ele levanta um questionamento importante sobre a divulgação de notas individuais por escola: alguns profissionais da educação encaram essa avaliação como competição entre escolas da mesma região, desviando o real objetivo da aprendizagem. O autor ainda explica a importância de melhorar o currículo escolar, almejando uma base curricular comum a todos e sanando as deficiências apresentadas por região, através de projetos que visam nivelar o ensino de maneira eficaz. 
Vale ressaltar que, se o Brasil alcançasse as metas estipuladas pelo PNE, seria de grande valor para educação. Como podem ser observadas acima, as metas foram feitas pensando em melhorar os índices da educação, no âmbito interno, com SINAEB e ENEM, e externo com o PISA. O plano previu políticas de valorização dos professores e estipulou o aumento do financiamento do PIB para 10\% para a educação básica (HYPOLITO, 2015).

Conforme a Lei no 9.394 (BRASIL, 1996, p. 1), “a educação abrange os processos formativos que se desenvolvem na vida familiar, na convivência humana, no trabalho, nas instituições de ensino e pesquisa, nos movimentos sociais e organizações da sociedade civil e nas manifestações culturais". A abordagem sobre as políticas educacionais se justifica pela busca de uma reflexão sobre as ações que vêm sendo desencadeadas por tais políticas que nortearam a organização do sistema educacional no Brasil.

\section{MÉTODO DE ENSINO FINLANDÊS}

O mundo globalizado e os avanços da tecnologia exigem mais capacidade intelectual da sociedade como nunca visto. As intensas transformações geradas pela rapidez da informação modificaram a sociedade em suas relações cotidianas e suas percepções sobre o mundo. Nesse sentimento, nascem novos métodos de ensino para acompanhar tais inovações e formar cidadãos conscientes de seu papel e do seu dever na sociedade contemporânea (GARCEZ, 2014).

Nessa perspectiva, o estudo se propôs analisar a educação brasileira e o modelo de ensino proposto pela Finlândia e questiona-se de onde veio a inspiração para um método de ensino que contraria os princípios tradicionais, utilizados por grande parte do mundo? Leite (2015) esclarece que o método utilizado nesse país é similar ao da Escola da Ponte e sua principal diferença para o método tradicional é o estudo fundamentado em fenômenos ou conteúdos, substituindo a aprendizagem por disciplinas. "A avaliação é sistemática e contínua, não são realizadas provas", mas, nem por isso eles deixam de avaliar, um dos métodos mais utilizados é a observação referente ao desenvolvimento dos alunos durante as atividades em classe (LEITE, 2015, p.13). 
A Escola da Ponte é de origem portuguesa e seu método de ensino é pautado na gestão democrática do currículo. Os princípios deste método levam em consideração: o respeito ao ritmo de aprendizado da criança, a construção de espaços para debates, o respeito a palavra, os hábitos de disciplina, o acompanhamento individual por tutores durante todo o processo letivo, o planejamento diário e quinzenal de estudos. O método considera também a prática de autoavaliações, seja por parte do aluno ou professor, visando corrigir e melhorar os métodos para atingir seus objetivos acadêmicos, além da ausência de aulas maçantes (PACHECO; PACHECO, 2015).

Se tratando de métodos ativos para educação, não poderia deixar de mencionar o Método Montessori, criado por Maria Montessori, uma médica italiana. Sua ideia é estimular a criança a aprender sozinha, sendo este método, muito utilizado na educação infantil e juvenil. O método visa incentivar a busca pelo conhecimento através da autonomia, com ambiente equipado para estimular a curiosidade do aluno, além de estimular habilidades físicas e psicológicas, propiciando o convívio social saudável (RIBAS et al., 2019).

O Método Montessori estimula o aprendizado, em espaço organizado e em contato com o meio ambiente, quando possível. Utiliza ferramentas simples, como: "brincadeiras individuais e coletivas, exercícios físicos e intelectivos, experiências sensoriais com música, arte e criações diversas, de maneira que venham a favorecer o desenvolvimento integral e totalizante da criança enquanto ser humano" (OLIVEIRA; SILVA; BITTENCOURT, 2015, p.208).

A Finlândia considerou os princípios dos métodos da Escola da Ponte e Montessori, e harmonizou estes conceitos, inovando a forma de ensino. Hoje, é vista como um dos principais modelos de ensino com alto desempenho do mundo e vem sendo destaque na educação desde 2001, confirmado pelos notáveis resultados no teste do PISA. "Destaca-se o conclusivo entendimento de que existem sistemas educacionais alternativos exitosos, cujos pressupostos se opõem profundamente ao padrão corporativo global de educação, os quais podem servir como modelo educacional a ser buscado por outras nações" (BASTOS, 2017, p. 802).

Em 2001, as revistas de educação e o noticiário de todo o mundo abriram os olhos para a Finlândia, um país localizado no norte do continente europeu. Segundo Britto (2013, p.5), a Finlândia é um país discreto e inovador, "mais conhecido pelo frio 
e pela empresa Nokia, uma das líderes mundiais no setor de telefonia móvel". Foi uma surpresa esse país assumir médias educacionais melhores que países como os EUA, Alemanha e França no teste do PISA. "Surpreendentemente, assumiu os primeiros lugares nos três domínios cognitivos avaliados pelo teste - Matemática, Ciências e Leitura" (BASTOS, 2017, p. 804).

A economia da Finlândia era pautada em exportações de celulose, papel e madeira até metade do século XX. Houve um crescimento considerável na economia desde os anos 2000. O Governo iniciou investimentos na indústria de eletroeletrônicos, equipamentos e produtos químicos. Em 2011, a renda per capita anual girava, aproximadamente, em 38 mil dólares americanos. Nos dias atuais, a economia do país é bastante estável, a sociedade é avançada tecnologicamente e competitiva e, também, apresenta-se, com um dos melhores índices de bem-estar social. Para se tornar um dos países mais inovadores do mundo, o foco foi investir e incentivar as pesquisas de ponta. Houve parceria entre instituições de ensino superior para o desenvolvimento de novas tecnologias, o que impulsionou o empreendedorismo (BRITTO, 2013).

Uma das principais reformas educacionais realizadas na Finlândia aconteceu no ano de 1990. Não haviam muitas exigências na nova agenda escolar, ela não impôs testes para avaliar seus alunos, não incentivou a competição entre escolas, não permitiu a mercantilização do ensino e não implantou um conceito severo de política educacional. No entanto, fortaleceu o ensino básico e criou programas de educação profissional adaptados ao ensino médio, atentando para uma educação igualitária e de excelência para toda a população (MORAES, 2017).

A reforma educacional de 1968 passou o ensino básico de 6 anos para 9 anos. Apenas 3\% da população utiliza o ensino particular, 97\% utilizam o ensino público conforme dados de 2013. Durante o processo de reforma da educação, houve investimentos do governo, apoio de comitês e especialistas da educação, organização e participação da sociedade nas escolas. É, também, interessante considerar, nessa perspectiva, que, para alcançar o êxito no sistema educacional, a Finlândia vem investindo a quase 50 anos, priorizando a educação na gestão pública por meio de investimentos governamentais e reformas educacionais (BRITTO, 2013, p. 19).

O sistema de educação finlandês segue um modelo pouco usado em países desenvolvidos, como Inglaterra e EUA. Todavia, cabe ressaltar que existe um 
pensamento em comum entre esses países, a consciência do dever social que a educação deve cumprir na sociedade, que são: igualdade e direito ao ensino de qualidade a todos. O método de ensino finlandês contrapõe às regras tradicionalistas de ensino, exemplo disso é a ausência de provas escritas como teste de aprendizagem de caráter eliminatório (MORAES, 2017).

Moraes (2017) ainda ressalta que as provas não têm caráter excludente, não servem para recompensar e nem constranger nenhum aluno, apenas serve para informar aos docentes se o trabalho desenvolvido está dando o resultado esperado. Além disso, existe um acompanhamento para os alunos com dificuldade na aprendizagem, os alunos contam com atenção exclusiva de profissionais treinados para ajudar a superar os desafios do conhecimento. A profissão do educador é valorizada, com isso, os docentes têm a sua admiração social preservada.

É importante considerar que a educação é uma troca de informações de uma geração para outra. Os professores são a peça-chave em todo esse processo, sendo assim, a carreira profissional de um educador deve ser algo para se orgulhar, entretanto, percebe-se essa falta de motivação aos profissionais da educação do Brasil. Nessa conjuntura do saber, é necessário valorizar o conhecimento de quem o transmite na “direção da preservação de uma civilização que contenha possibilidades melhores de vida e participação de todos" (GATTI, 2016, p. 162).

Segundo Carvalho (2016), a valorização da docência na Finlândia é um dos segredos para o sucesso no âmbito educacional. Britto (2013, p. 10) explica que a "qualificação docente é hoje considerada pedra angular do sistema educacional finlandês". Recorda que durante a implantação da reforma educacional, o governo destinou investimento para motivar e valorizar a profissão de mestres. Devido a isso, a carreira de professor é uma das mais respeitadas do país, com salários justos, plano de carreira e ambiente propício para o desenvolvimento do trabalho com os alunos. Segundo o autor, todo sistema educacional eficiente deve investir em seu profissional educador. Para uma educação de qualidade, é "imprescindível contar com um corpo docente altamente qualificado" (BRITTO, 2013, p. 9).

Louzano et al., (2010) destaca a importância da qualificação dos docentes em seu estudo intitulado: "Quem quer ser professor". A exigência para atuar como professor na Finlândia é ter, no mínimo, o título de mestre, mesmo sendo para o ensino 
fundamental. Britto (2013) completa que os professores finlandeses não recebem mais que professores da Alemanha e Cingapura, países que se destacam nos níveis da educação, conforme avaliação da OCDE. No entanto, o prestígio social parece ser um fator motivador para esses profissionais, destacando-se a valorização do capital humano, as condições de trabalho e a flexibilidade para desempenhar a função.

Tal flexibilidade inspirou os educadores finlandeses a trabalharem certos conteúdos de forma conjunta. $\mathrm{O}$ ensino por tópicos multidisciplinares tem se tornado relevante para o ensino finlandês e faz sucesso entre os alunos. Mas, como funciona este método? É quando os professores de disciplinas diferentes se juntam na mesma aula, porém, atentos ao tema central. Cada professor colabora com a sua disciplina dentro do assunto escolhido. Exemplo: Aula de biologia "sobre Ecossistema Polar Ártico", os professores se reúnem e preparam uma aula inovadora. Estes são profissionais mestres em Biologia, Química, Geografia e Matemática (CARVALHO, 2016, p. 96).

Dados estatísticos da Finlândia divulgados pelo Statistics Finland (2019) indicam que as escolas abrangentes tinham 564.100 alunos no ano de 2019. O número aumentou $0,6 \%$ em comparação ao período anterior. No total, 11,6\% dos alunos receberam apoio intensificado, 8,5\% receberam apoio especial, 437 crianças em idade escolar estavam recebendo ensino em casa e 668 crianças foram adiantadas em um ano no início da educação básica. O total de alunos do ensino pré-primário era de 59.652, onde 9.445 estavam no ensino pré-primário e 50.207 em creches. No ano de 2019, havia 2.288 escolas abrangentes ativas no país, sendo 95\% destas administradas pelos municípios, e indicando 53 escolas a menos do que as registradas no período anterior.

Outro fator observado pelo PISA, é que as escolas finlandesas são bem homogêneas em relação à equidade no ensino, o que gera nota 6 em proficiência pela análise da OCDE. O país é considerado com baixo índice de desigualdade social em comparação à outros países do mundo, mesmo existindo diferenças culturais e socioeconômicas de uma região para outra. "Além disso, o país é bastante igualitário: o coeficiente de Gini $^{1}$ é de 0,26 , em uma escala em que 0 equivale à igualdade perfeita e 1, à desigualdade total” (BRITTO, 2013, p. 8).

\footnotetext{
${ }^{1} \mathrm{O}$ coeficiente de Gini é também chamado de Índice de Gini, é um dado estatístico utilizado para avaliar a distribuição das riquezas de um determinado lugar. Esse índice recebe esse nome em homenagem ao seu desenvolvedor, o estatístico italiano Corrado Gini, que elaborou esse conceito em 1912 (MEDEIROS; BARBOSA; CARVALHAES, 2019).
} 
O currículo escolar na Finlândia vai além do ensino pedagógico em sala de aula, incluindo também práticas e valores para a vida toda. Por exemplo, as crianças, desde o primeiro ano, participam de atividades como: cuidar do jardim da escola, auxiliar na cozinha, ajudar na biblioteca, participar da reciclagem de papel, dentre outras atividades que visam manter o ambiente escolar agradável. Os alunos são acompanhados pelos funcionários das escolas responsáveis por essas tarefas. Esse método almeja trabalhar a consciência da criança sobre a importância de respeitar e amar o ambiente escolar como se fosse a sua segunda casa (BRASIL, 2011).

As instituições educacionais finlandesas que compreendem o ensino fundamental, tem como incentivo "uma refeição quente por dia, assistência médica e odontológica, orientação educacional e acompanhamento psicológico para todos os estudantes, independentemente de comprovação de carência”. O uso da tecnologia para auxiliar os alunos nas aulas também é fortemente estimulado, são utilizados aplicativos gratuitos para dinamizar as aulas e ajudar os alunos a fixar os conteúdos. Além de contar com um corpo docente altamente preparado e motivado para auxiliar os alunos em seu processo de aprendizagem (BRITTO 2013, p. 9).

Assim como os alunos finlandeses, os alunos brasileiros têm experimentado essa experiência digital utilizando o aplicativo TME, que é um dos "aplicativos educacionais gratuitos" que proporciona treinamentos em várias disciplinas, sendo que, matemática e língua estrangeira são as mais procuradas. O uso de Smartphones se tornou habitual em nosso cotidiano, tornando fácil o acesso às informações. "Porém, a falta de iniciativas na criação de aplicativos dessa natureza e a mudança cultural de muitos docentes ainda são os principais desafios encontrados" (ARANTES; SEABRA, 2016, p. 10).

Na Finlândia, existe um forte incentivo para a educação continuada, a educação superior finlandesa é quase toda gratuita. $\mathrm{O}$ aluno, ao concluir o ensino médio, faz um exame nacional de matrícula, sendo aprovado, faz o pagamento de uma taxa anual e continua os seus estudos. As universidades que oferecem cursos de pós-graduação como mestrado e doutorados, têm autonomia administrativa, o governo incentivou que elas aumentassem a sua eficiência para continuar recebendo investimento estatal (BRITTO, 2013). 
Segundo o mesmo autor, o exame nacional de matrícula avalia os quatro campos do saber, sendo eles: "O exame é obrigatório em Língua Materna e os alunos podem escolher três entre as seguintes áreas: Segunda Língua Nacional (finlandês ou sueco); Línguas Estrangeiras; Matemática e Estudos Gerais (incluindo Ciências Sociais e Naturais)". Outro fator importante é a integração do ensino médio com cursos profissionalizantes, valorizando o currículo individual de cada aluno (BRITTO, 2013, p. 10).

Percebe-se que a capacidade de inovar nos métodos de ensino ainda é um obstáculo para as escolas brasileiras. Apesar das inúmeras reformas políticas no âmbito educacional, muitas escolas não conseguiram se adequar às novas metodologias de ensino. Nota-se que as escolas federais e particulares apresentam melhores resultados que as escolas públicas. "Uma das principais dificuldades no processo de ensino e aprendizagem é conseguir instigar o interesse do discente ao estudo. A escola tal como é apresentada aos adolescentes é desinteressante e parece desconsiderar todo o seu convívio em sociedade" (GARCEZ, 2014, p. 26).

\section{INDICADORES INTERNOS E EXTERNOS DA EDUCAÇÃO BÁSICA}

O o Índice de Desenvolvimento da educação básica (IDEB) foi uma das primeiras iniciativas brasileiras para determinar as metas a fim de alcançar o êxito educacional, ele pode ser definido como um indicador nacional de qualidade da educação. Foi elaborado em 2007, pelo Instituto Nacional de Estudos e Pesquisas Educacionais Anísio Teixeira (INEP), formulado para medir a qualidade do aprendizado nacional, utiliza dados concretos e a sua principal fonte de dados é retirada dos resultados das avaliações da Prova Brasil e SAEB (INEP, 2020).

O Inep (2020) explica como se faz o cálculo para determinação do desenvolvimento da educação básica, que consiste em dois componentes: a taxa de rendimento escolar (aprovação) apurada no censo escolar aplicado todo ano, e as médias de avaliações aplicada pelo Saeb, realizado a cada dois anos nas escolas, a meta deste programa é alcançar 6 pontos nas escolas públicas até 2021.

Uma das principais ferramentas de coleta de dados do Inep é o SINAEB, que são testes nacionais aplicados nas escolas, tanto da rede pública como da rede privada, o 
que gera uma amostra ampla do ensino brasileiro. Esses testes acontecem a cada a cada dois anos, para os alunos do $5^{\circ}$ ao $9^{\circ}$ do ensino fundamental e $3^{\circ}$ ano do ensino médio do sistema educacional (BRASIL, 2019).

O indicador externo que mede a qualidade do ensino foi criado pela Organização para a Cooperação e Desenvolvimento Econômico(OCDE). Tal indicador é denominado de Programa Internacional de Avaliação de Estudantes (PISA) que avalia a educação em mais de 70 países a cada 3 anos, sua finalidade é medir a qualidade da educação em nível mundial. "Uma maneira de observar o ritmo em que os sistemas educacionais têm se expandido nos países é analisar as taxas de conclusão de diferentes gerações" (OCDE, 2015, p. 1).

A OCDE já conta com 35 países associados, dentre eles economias fortes, como a Alemanha, a França, a Finlândia, os Estados Unidos, a Noruega e o Reino Unido. A sua fundação ocorreu em 1961, sendo sucessora da Organização para a Cooperação Econômica Europeia, criada em 1948 (BRASIL, 2019). Segundo a OCDE, "a governança corporativa é o sistema em que as sociedades do setor público e privado são dirigidas e controladas" (MARQUES, 2007, p. 14).

A relevância da análise sobre o relatório da OCDE, frente às perspectivas do Brasil no âmbito educacional, justifica-se pelo contexto atual em que se vive o país, apresentando dificuldades para se equiparar com as diretrizes propostas pela OCDE e constituindo conflitos em relação ao desenvolvimento educacional, social, político e econômico pela ótica global (BRASIL, 2019).

Segundo o Ministério da Educação, o resultado do PISA 2015, aplicado aos alunos de 15 a 16 anos no Brasil, foi preocupante, a média nacional ficou em 401 pontos, ficando aquém da estimativa proposta pela Lei n. 13.005/2014, que estipulou 438 pontos. Não se compara então com a média dos países membros da OCDE, que são 493 pontos. Destacou-se nesta avaliação o estado do Espírito Santo com 435 pontos, sendo a melhor média nacional, e o Estado do Alagoas com a pior média, com 360 pontos (BRASIL, 2019).

Após a análise do fracasso no PISA 2018, o Ministério da Educação reconheceu em nota que os alunos brasileiros estão quase 3 anos atrás do índice de proficiência dos países da OCDE. O Brasil ocupa a posição $59^{\circ}$ em literatura, em matemática $69^{\circ}$ e em ciências $64^{\circ}$. Analisando a eficiência por região, observa-se que o Centro Oeste e o 
Sudeste possuem um rendimento educacional melhor que a região Norte e Nordeste do país (BRASIL, 2019).

\section{CONSIDERAÇÕES FINAIS}

Ao contextualizar a história da educação, observa-se que a deficiência no processo de alfabetização e libertação do Brasil colônia, foi uma herança deixada pela colonização portuguesa. Esse fato histórico reflete-se até hoje na educação brasileira. Logo após, o Brasil enfrentou a luta das elites pelo poder e o aumento da desigualdade social. Somente a partir do golpe militar de 1964 é que as reformas educacionais começaram a surtir efeito na sociedade e alcançar a maioria da população.

Nota-se que, na história de países com uma forte economia ao longo de sua trajetória, houve uma priorização da educação com o alcance de uma qualidade elevada. Os Estados Unidos da América, em sua parte central, foi colonizado pelos franceses e, o sudeste pelos espanhóis, é hoje uma grande potência mundial. Outro exemplo que pode ser citado são as colonizações britânicas, em países também desenvolvidos, como o Canadá e Austrália. A forma de colonização desses países trouxe desenvolvimento social e econômico e junto os princípios de uma educação igualitária a todos (FORTES, 2012).

O motivo de tantas reformas e criação de leis teve a finalidade de tentar corrigir as lacunas na legislação educacional, que, ao longo do tempo, não obtiveram o êxito esperado, quando comparado a países desenvolvidos. Na contextualização da educação exposta neste estudo, percebe-se que a dificuldade do Brasil está em fazer cumprir as políticas públicas formuladas para a educação e em promover a aprendizagem aos jovens e crianças de maneira eficaz. O país oferece escolas por todo território nacional, mas essas estão debilitadas, seja na estrutura ou na desmotivação dos profissionais que atuam neste setor (BITTAR; BITTAR, 2012).

$\mathrm{O}$ estudo expõe o art. $2^{\circ}$ do PNE que resume em dez diretrizes os principais objetivos a serem alcançados. Observa-se, dentre as diretrizes, a preocupação de generalizar o ensino fundamental e médio, garantindo que mais jovens possam cumprir os estudos na faixa etária adequada. O PNE sugere também o aumento da taxa de 
alfabetização, elevando a qualidade do ensino, tanto na rede básica como no ensino superior, e assim fomentar a taxa de pessoas portadoras de diploma superior no país.

Segundo dados do documento Statistics Finland (2019), no ano de 2018, a taxa de alunos que concluíram o ensino médio foi de $82 \%$. Comparando esse dado com o Brasil, conforme dados do IBGE (2018), pessoas acima de 25 anos somavam 47,4\% das portadoras do diploma do ensino médio completo. Houve uma melhora nessa taxa, que comparada ao ano anterior, apresentava 46,6\%. Observa-se que o Ministério da Educação tem incentivado a melhoria dos processos educacionais. Para que haja tal melhoria, o PNE precisa de investimento por parte dos governantes, apoio de toda a sociedade, e engajamento dos profissionais da educação.

Apesar do PIB brasileiro ser expressivo, o país se encontra atrás de países como Paraguai e Bolívia, no ranking da educação. Então fica a pergunta: por que não investir mais na educação? Por que as políticas públicas de educação não funcionam no Brasil? Por que a educação, tanto no período colonial, como no imperial, sempre foi para as elites? O Brasil precisa investir em uma educação igualitária em qualidade, em que a rede pública equipara ao ensino da rede privada, diminuindo o abismo entre o universo dos ricos e o mundo dos mais necessitados, dando oportunidade de ensino a todos (FORTES, 2012).

Por fim, os indicadores da educação, como o PISA e o IDEB, revelam um sistema educacional desigual muito distante de ser comparado com a qualidade de ensino ofertada no país finlandês ou mesmo nos países membros da OCDE. O estudo aqui apresentado sobre a educação finlandesa pode ensinar muito para a educação brasileira mesmo com as diferenças culturais e sociais (SOARES, 2007).

O desafio de proporcionar educação de qualidade a todos parece grande e a democracia continuará carente se o povo não tiver condições de opinar nas decisões políticas e participar ativamente da sociedade. Isso só será possível com uma sociedade letrada, que a educação cumpra o seu dever social com o objetivo do bem comum a todos ao estimular um pensamento crítico aos indivíduos sobre a situação em que se vive (FREIRE, 2014).

Segundo Leite (2018, p.12), “o índice de Gini é um coeficiente de mensuração da desigualdade que varia entre zero e um, utilizado principalmente em estudos sobre a distribuição de renda". No desenvolvimento do referencial teórico deste estudo, Britto 
(2013) citou o índice de Gini da Finlândia, como sendo 0,26 em 2012. Ao comparar com o Brasil, o índice de Gini foi de 0,52 no período de 2012 a 2015 e aumentou para 0,54 no ano de 2018, conforme apurado em pesquisas pelo IBGE (2019). Este dado aponta a desigualdade existente entre os dois países comparados neste estudo. A desigualdade social influencia diretamente o sistema educacional como um todo e dificulta o acesso ao ensino devido às circunstâncias, como por exemplo, ter que trabalhar para ajudar no sustento da família, deixando de priorizar a educação.

Observa-se que o Brasil e a Finlândia possuem realidades bem diferentes, começando pelo tamanho do território: a Finlândia possui $338.424 \mathrm{~km}^{2}$, que corresponde à medida mais próxima do estado de Goiás no Brasil, com 340.111 km², de acordo com o IBGE (2020). As escolas finlandesas atenderam 564.100 alunos na educação básica, o site finlandês Statistics Finland (2019). O Brasil teve 43,3 milhões de estudantes matriculados no mesmo ano. Estão inseridas nesse número a educação infantil e o ensino fundamental e médio, conforme dados do INEP (2019). Além da diferença entre os números citados aqui, existe a diferença econômica e de oportunidades. Estes fatores explicam as dificuldades do Brasil, em acompanhar os modelos de alto desempenho educacionais, utilizados em países desenvolvidos.

A reflexão aqui proposta revela dois sistemas educacionais antagônicos, em que a Finlândia é moderna e flexível, e o Brasil tem buscado melhorar as metodologias de ensino, porém sem muito êxito na prática da rede pública, assim revelado pelos exames do PISA. Observa-se que uma base educacional comum a todos e com qualidade faz toda a diferença para o desenvolvimento do ser humano ao longo da sua vida. O Brasil tem uma vasta diversidade cultural, econômica e social. Fatores estes que influenciam diretamente a qualidade do ensino. Além disso, existem fatores que fogem ao controle da escola, como a miséria e a fome, a falta de estrutura familiar, dentre outros agravantes gerados pela desigualdade de oportunidades.

\section{REFERÊNCIAS}

AMARAL, N. C. PEC 241/55: a "morte" do PNE (2014-2024) e o poder de diminuição dos recursos educacionais. RBPAE, v. 32, n. 3, p. 653-673, set./dez. 2016. 
ARANTES, Hannderson; SEABRA, Rodrigo. TME: Aplicativo M-Learning para o Estudo de Conceitos Matemáticos com Ênfase no ENEM. Simpósio Brasileiro de Informática na Educação-SBIE, 2016, p. 1.

BASTOS, REMO MOREIRA BRITO. O surpreendente êxito do sistema educacional finlandês em um cenário global de educação mercantilizada. Revista brasileira de Educação, v. 22, n. 70, p. 802-825, 2017.

BITTAR, Marisa; BITTAR, Mariluce. História da Educação no Brasil: a escola pública no processo de democratização da sociedade. Acta Scientiarum. Education, v. 34, n. 2, p. 157-168, 2012.

BRANDÃO, Carlos Rodrigues. O que é educação. São Paulo: Editora Brasiliense, coleção primeiros passos, 2007.

BRASIL. Decreto n. 9393, de 19 de dezembro de 1996. Diário Oficial da União, Brasília, DF, 20 de dezembro de 1996.

Ministério da Educação. Decreto n. 13.005, de 25 de junho de 2014. Diário Oficial da União, Brasília, DF, 25 de junho de 2014.

$<$ https://www.co

Congresso Nacional. Medida Provisória 126992. Disponível em: ngressonacional.leg.br/materias/medidas-provisorias/-/mpv/126992> Acesso em: 24 nov. de 2019.

<http://portal.me

Ministério da Educação. Portal do MEC. REUNI. Disponível em: c.gov.br/reuni-sp-93318841>. Acesso em: 21 nov. de 2019.

$<$ http://portal.mec.g

Ministério da Educação. Portal do MEC. PISA. Disponível em: ov.br/busca-geral/211-noticias/218175739/83191-pisa-2018-revela-baixo-desempenhoescolar-em-leitura-matematica-e-ciencias-no-brasil>. Acesso em: 18 jan. de 2020.

$<$ http://portal.mec.g ov.br/busca-geral/211-noticias/218175739/17273-brasil-troca-experiencias-com-afinlandia-em-educacao-basica>. Acesso em: 22 abril de 2020.

Ministério da Fazenda. OCDE (Organização para a Cooperação e Desenvolvimento Econômico). Disponível em: $<\mathrm{http}$ ///www.fazenda.gov.br/assuntos/atuacao- internacional/coo peracao-internacional/ocde>. Acesso em: 22 nov. 2019.

$<$ http://

Ministério da Educação. PNE. Plano Nacional de Educação. Disponível em: pne.mec.gov.br/>. Acesso em: 21 nov. 2019. 
BRITTO, Tatiana F. O que é que a Finlândia tem? Notas sobre um sistema educacional de alto desempenho. Textos para Discussão, n. 129, 2013.

BRITTO, Tatiana Feitosa de. O que distingue o sistema educacional de alto desempenho da Finlândia? 2015.

CARNOY, Martin et al. A educação brasileira está melhorando? Evidências do Pisa e do Saeb. Cadernos de Pesquisa, v. 45, n. 157, p. 450-485, 2015.

CARVALHO, Renato. Finlândia será o primeiro país do mundo a abolir a divisão do conteúdo escolar em matérias. Interdisciplinaridade. Revista do Grupo de Estudos e Pesquisa em Interdisciplinaridade. ISSN 2179-0094., n. 8, p. 96-97, 2016.

ESTATÍSTICAS OFICIAIS DA FINLÂNDIA (OSF): Educação escolar pré-primária e abrangente [publicação eletrônica]. ISSN $=1799-3725$. 2019. Helsinque: Statistics Finland [referido em 5.4.2020].Disponível em: <http://www.stat.fi/til/pop/2019/pop_2019_2019-11-1

4_tie_001_en.html>. Acesso em : 17 de abril de 2020.

FREIRE, Paulo. Educação como prática da liberdade. São Paulo: Editora Paz e Terra, $\mathrm{n}^{\circ} 1405,1967$.

FREIRE, Paulo. Educação como prática da liberdade. São Paulo: Editora Paz e Terra, $1^{1}$ ed. [recurso eletrônico] 2014.

GARCEZ, Edna Sheron da Costa et al. O Lúdico em ensino de Química: um estudo do estado da arte. 2014.

GATTI, Bernardete A. Formação de professores: condições e problemas atuais. Revista Internacional de Formação de Professores, v. 1, n. 2, p. 161-171, 2016.

GIOLO, Jaime. Educação a distância: tensões entre o público e o privado. Educação \& Sociedade, v. 31, n. 113, p. 1271-1298, 2010.

GONÇALVES, Nadia G. Doutrina de Segurança Nacional e Desenvolvimento na ditadura civil-militar: estratégias e a educação. XXVI Simpósio Nacional de História, p. 1-17, 2011.

IBGE- Instituto Brasileiro de Geografia e Estatística. Disponível em: $<$ https://educa.ibge.gov.

br/jovens/conheca-o-brasil/populacao/18317-educacao.html>. Acesso em: 11 de abril de 2020.

Instituto Brasileiro de Geografia e Estatística. Disponível em: $<$ https://agenciadenoticia

s.ibge.gov.br/agencia-sala-de-imprensa/2013-agencia-de-noticias/releases/25700-pnadcontiua-2018-10-da-populacao-concentram-43-1-da-massa-de-rendimentos-do-pais>. 
Acesso em: 20 de abril de 2020.

INEP. Instituto Nacional de Estudos e Pesquisas Educacionais Anísio Teixeira. Disponível em: <http://www.inep.gov.br/>. Acesso em: 21 nov. 2019.

Instituto Nacional de Estudos e Pesquisas Educacionais Anísio Teixeira. Disponível em: <http://portal.inep.gov.br/conheca-o-inep>. Acesso em: 10 jan. 2020.

Instituto Nacional de Estudos e Pesquisas Educacionais Anísio Teixeira.

Disponível

em: <http://download.inep.gov.br/educacao_basica/portal_IDEB/o_que_sao_as_metas/Artig o

_projecoes.pdf >. Acesso em: 15 jan. 2020.

Instituto Nacional de Estudos e Pesquisas Educacionais Anísio Teixeira.

Disponível

em: <http://download.inep.gov.br/educacao_basica/portal_IDEB/planilhas_para_download/ 20

17/ResumoTecnico_IDEB_2005-2017.pdf>. Acesso em: 20 jan. 2020.

LOUZANO, Paula et al. Quem quer ser professor? Atratividade, seleção e formação do docente no Brasil. Estudos em Avaliação Educacional, v. 21, n. 47, p. 543-568, 2010.

MARQUES, Maria da Conceição da Costa. Aplicação dos princípios da governança corporativa ao sector público. Revista de Administração Contemporânea, v. 11, n. 2, p. 11-26, 2007.

MARTA, Viviane Gomes. A utilização do youtube como aliado no desenvolvimento das dez competências gerais da BNCC. 2018.

MESQUIDA, Peri. Catequizadores de índios, educadores de colonos, Soldados de Cristo: formação de professores e ação pedagógica dos jesuítas no Brasil, de 1549 a 1759, à luz do Ratio Studiorum. Educar em Revista, n. 48, p. 235-249, 2013.

LIMA, Telma Cristiane Sasso de; MIOTO, Regina Célia Tamaso. Procedimentos metodológicos na construção do conhecimento científico: a pesquisa bibliográfica. Revista Katálysis, v. 10, n. SPE, p. 37-45, 2007.

LEITE, Acácio Zuniga. Análise da concentração fundiária no Brasil: desafios e limites do uso do índice de Gini. Revista NERA, ano 21, n. 42, p. 10-28, mai.- ago. 2018.

MEDEIROS, Marcelo; BARBOSA, Rogério, J.; CARVALHAES, Flavio. Educação, desigualdade e redução da pobreza no Brasil. Texto para Discussão, 2447, Rio de Janeiro: IPEA, 2019.

MORAES, Carmen Sylvia Vidigal. O ensino médio e as comparações internacionais: Brasil, Inglaterra e Finlândia. Educação \& Sociedade, v. 38, n. 139, p. 405-429, 2017. 
OCDE. Organização para a Cooperação e Desenvolvimento Econômico. Relatório Econômico OCDE: Brasil 2018. Disponível em: $<$ http://www.oecd.org/economy/surveys/Bra zil-2018-OECD-economic-survey-overview-Portuguese.pdf > Acesso em: 19 de jan. 2020.

Education at a Glance 2015: OECD Indicators, OECD Publishing, Paris, Disponível em: <https://www.oecd.org/brazil/Education-at-a-glance-2015-Brazil-inPortugue se.pdf >. Acesso em: 22 nov. 2019.

OGIBA, Sônia Mara Moreira. Garantia do Direito à Educação: monitorando o PNELei $\mathrm{n}^{\circ}$ 13.005/2014. 2018.

OLIVEIRA, Marta Regina Furlan de; SILVA, Anilde Tombolato Tavares de; BITTENCOURT, Candida Alayde de Carvalho. Experiências montessorianas no projeto de extensão ludoteca em movimento da Universidade Estadual de Londrina. Revista HISTEDBR On-Line, v. 15, n. 63, p. 280-292, 2015.

PACHECO, José; DE FÁTIMA PACHECO, Maria. Escola da Ponte: uma escola pública em debate [livro eletrônico]. Cortez Editora, São Paulo, 2015.

PONTES, de Márcio Matoso. A temática 'Probabilidade e Estatística' nos anos iniciais do Ensino Fundamental a partir da promulgação da BNCC: percepções pedagógicas. Revista de Estudos e Pesquisas sobre Ensino Tecnológico (EDUCITEC), v. 5, n. 12, 2019.

RIBAS, Alexandre Cristina; FONTOURA, Camila Figueira; WENDT, Ludmila Pause; PIEVE, Maria das Graças Prediger da. Educação Sensorial- O Método de Maria Montessori. Revista do Seminário de Educação de Cruz Alta - RS, [S.1.], v. 6, n. 1, p. 523-524, 2019.

SAVIANI, Dermeval. Escola e democracia. Rio de Janeiro: Editora Autores Associados, 2018.

SOARES, José Francisco; CANDIAN, Juliana Frizzoni. O efeito da escola básica brasileira: as evidências do PISA e do SAEB. Revista Contemporânea de Educação, v. 2, n. 4, p. 163-181, 2007.

VIEIRA, Carlos Eduardo. O Movimento pela Escola Nova no Paraná: trajetória e idéias educativas de Erasmo Pilotto. Educar em Revista, v. 17, n. 18, p. 53-73, 2001.

YOUNG, Michael F. D. Por que o conhecimento é importante para as escolas do século XXI? Cadernos de Pesquisa, v. 46, n. 159, p. 18-37, 2016. 